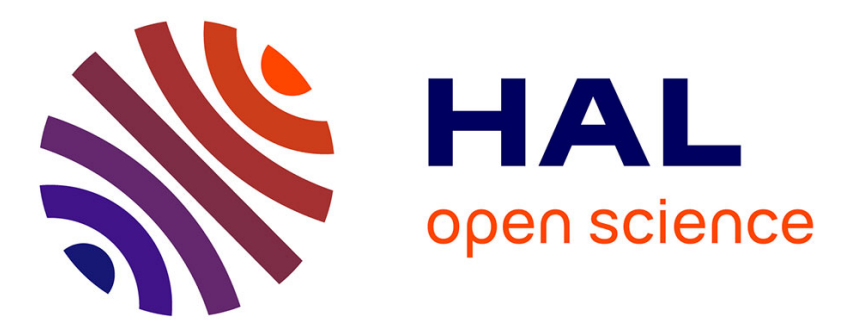

\title{
Origin of Small-Angle Scattering from Contrast-Matched Nanoparticles: A Study of Chain and Filler Structure in Polymer Nanocomposites
} Amélie Banc, Anne-Caroline Genix, Christelle Dupas, Michael Sztucki, Ralf Schweins, Marie-Sousai Appavou, Julian Oberdisse

\section{To cite this version:}

Amélie Banc, Anne-Caroline Genix, Christelle Dupas, Michael Sztucki, Ralf Schweins, et al.. Origin of Small-Angle Scattering from Contrast-Matched Nanoparticles: A Study of Chain and Filler Structure in Polymer Nanocomposites. Macromolecules, 2015, 48 (18), pp.6596-6605. 10.1021/acs.macromol.5b01424 . hal-01203353

\section{HAL Id: hal-01203353 https://hal.science/hal-01203353}

Submitted on 5 May 2020

HAL is a multi-disciplinary open access archive for the deposit and dissemination of scientific research documents, whether they are published or not. The documents may come from teaching and research institutions in France or abroad, or from public or private research centers.
L'archive ouverte pluridisciplinaire HAL, est destinée au dépôt et à la diffusion de documents scientifiques de niveau recherche, publiés ou non, émanant des établissements d'enseignement et de recherche français ou étrangers, des laboratoires publics ou privés. 


\title{
On the origin of small-angle scattering from contrast-matched nanoparticles: A study of chain and filler structure in polymer nanocomposites
}

\author{
Amélie Banc ${ }^{1}$, Anne-Caroline Genix ${ }^{1 *}$, Christelle Dupas ${ }^{1}$, Michael Sztucki ${ }^{2}$, Ralf Schweins ${ }^{3}$, \\ Marie-Sousai Appavou ${ }^{4}$, Julian Oberdisse ${ }^{1}$ \\ ${ }^{1}$ Laboratoire Charles Coulomb (L2C), UMR 5221 CNRS-Université de Montpellier, F-34095 \\ Montpellier, France \\ ${ }^{2}$ European Synchrotron Radiation Facility, 71 Avenue des Martyrs, BP 220, F-38043, Grenoble Cedex 9, \\ France \\ ${ }^{3}$ Institut Laue-Langevin, 71 Avenue des Martyrs, CS 20 156, F-38042 Grenoble Cedex 9, France \\ ${ }^{4}$ Jülich Centre for Neutron Science JCNS, Forschungszentrum Jülich, Outstation at MLZ, D-85747 Garching, \\ Germany
}

$30 / 07 / 2015$

\begin{abstract}
The conformation of poly(ethyl methacrylate) chains in silica-latex-nanocomposites has been studied under zero-average contrast conditions (ZAC) using small-angle neutron scattering (SANS). Samples have been prepared by drying colloidal suspensions of silica and polymer nanoparticles (NPs) followed by thermal annealing, for two different silica NPs (radius of 5 and $15 \mathrm{~nm}$ ) and two chain molecular weights (17 and $100 \mathrm{~kg} / \mathrm{mol})$. By appropriate mixing of hydrogenated and deuterated polymer, chain scattering contrast is introduced, and in principle silica scattering suppressed. The silica structure consisting mostly of small fractal aggregates is characterized by transmission electron microscopy (TEM) and small-angle X-ray scattering (SAXS) on the same samples. The measurement of the chain structure by SANS, however, is perturbed by unwanted silica contributions, as often reported in the literature. Here, the contribution of contrast-matched silica is evidenced as a function of system parameters, namely chain mass, silica size, and volume fraction, and a model rationalizing these contributions for the first time is proposed. Based on a statistical analysis, a nanometer-thick polymer shell surrounding silica NPs is shown to create contrast, which is presumably maintained by the reduced mobility of polymer close to interfaces or attractive polymer-silica interactions. This shell is proven to be quantitatively important only for the smallest silica NPs. Finally, the pure polymer scattering can be isolated, and the polymer radius of gyration is found to be independent of filler content and NP size.
\end{abstract}




\section{Introduction}

Polymer nanocomposites combine the viscoelastic properties of polymer matrices with the hardness of embedded nanoparticles (NPs), and depending on the details of the microscopic NP dispersion, a very different rheological or mechanical behavior may be obtained ${ }^{1-4}$. Aggregates of NPs, e.g., are often formed, and the inclusion of polymer inside aggregates may increase the concentration of hard matter, and introduce volume spanning and sometimes fractal, percolating structures. ${ }^{5-11}$ On the other extreme, perfect individual dispersion offers a great polymer-filler interface, due to the high specific surface of NPs, and interactions between NPs and polymer may lead to new phenomena like dynamically slowed-down ("glassy") polymer bridges between NPs ${ }^{12-14}$. In the context of filler structure, one may also note that polymer grafting on NPs was shown to be an important parameter to tune NP dispersion, in model ${ }^{15,16}$ or industrially relevant systems ${ }^{17-19}$.

If it is important to characterize the microscopic filler structure precisely in order to understand macroscopic mechanical or rheological properties, the structure of the second ingredient, the polymer chains, is of equal importance. Experimentally, the radius of gyration $\left(\mathrm{R}_{\mathrm{g}}\right)$ of polymer chains in nanocomposites can be measured by small-angle neutron scattering (SANS) using the zero average contrast (ZAC) conditions by mixing hydrogenated $(\mathrm{H})$ and deuterated (D) chains in order to match the filler signal and measure only the chain form factor 20, 21. Over the past 15 years, considerable efforts have been dedicated to the measurement of chain conformation in polymer nanocomposites, with sometimes contradicting results, depending on the chemical system, the size ratio between polymer and filler, and filler concentration. ${ }^{22-33}$ To summarize these efforts, results appear to converge towards Gaussian statistics of chains, unperturbed by the presence of filler NPs, and exceptions seem to be due to system-dependent effects, like limited dispersion ${ }^{22}$, strong confinement ${ }^{28}$, particle softness ${ }^{23}$ or anisotropy ${ }^{32}$. Moreover, perfect contrast-matching was found to be almost systematically unattainable. Indeed, these studies displayed unexplained, polluted SANS signals in the low-q range, restricting the analysis of the chain conformation to the high-q region, without access to the Guinier regime, in spite of a careful determination of scattering length densities by independent contrast variation experiments to avoid such scattering contributions by the filler. Such contributions are usually known from small-angle X-ray scattering (SAXS) experiments on the same samples, which are insensitive to the polymer deuteration, and highlight the filler structure. 
Polymer nanocomposites may be formulated in many different ways. ${ }^{34-39}$ We have recently followed a silica-latex route where samples are formed by evaporation of aqueous solvent from colloidal suspensions of silica and nanolatex beads ${ }^{40}$. This method has been used since the 1990's and has the advantage of being free of organic solvent and allowing control of filler dispersion via electrostatic interactions between colloids in water before film formation. ${ }^{5,41}$ In this article, the structure of the silica has been studied in detail by SAXS and transmission electron microscopy (TEM) for two silica NP sizes, and two polymer chain masses. We then focus on the chain structure in these four systems measured by ZAC-SANS, identify samples where ZAC fails, and propose a possible mechanism of failure in polymer nanocomposites, depending on polymer mass and NP size. Finally, a model describing the silica contribution quantitatively is presented and compared to our data.

\section{Materials and methods}

Silica nanoparticles: Two different colloidal silica NPs have been used for the nanocomposite synthesis, Ludox TM40 and Ludox SM30. These aqueous colloidal suspensions were characterized by SAXS after dilution in deionized water. The scattered intensities were fitted with log-normal distributions of spherical objects in Figure 1: $R_{S i}=5$ $\mathrm{nm}, \sigma=16 \%$ for Ludox SM30 and $\mathrm{R}_{\mathrm{Si}}=14 \mathrm{~nm}, \sigma=11 \%$ for Ludox TM40. The good fits of the Ludox TM40 spectra indicate a very good dispersion of particles in water, whereas the Ludox SM30 spectra display additional intensity at low q, which is the signature of aggregation. The level of this intensity indicates an average aggregation number of 2.5 . Finally, the difference in low-q intensity in Figure 1 - keeping in mind that the TM40intensity level has been shifted for clarity - illustrates the difference in size. 


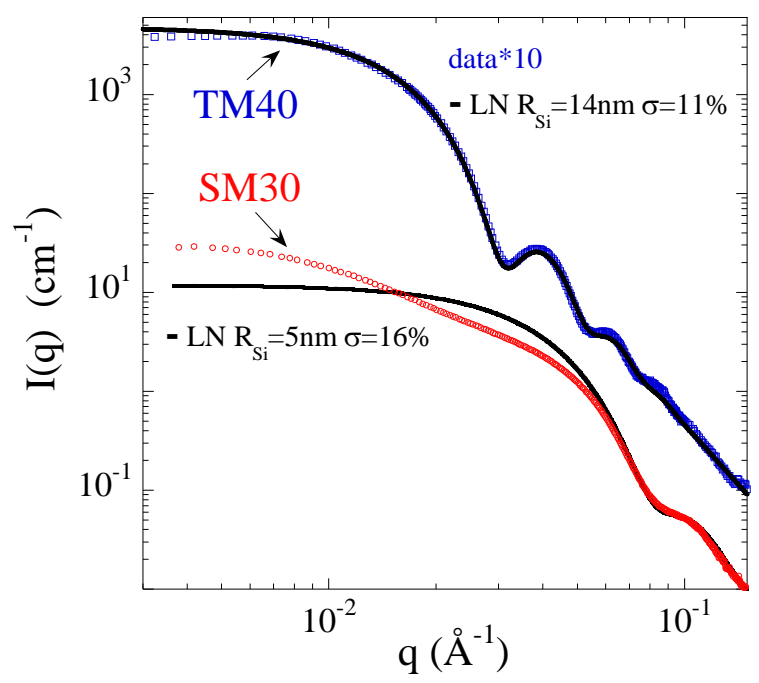

Figure 1. SAXS intensities (symbols) and modeling by log-normal distributions (LN, lines) of spherical particles of colloidal silica suspensions diluted in deionized water: Ludox SM30 at $0.22 \% \mathrm{v}$ and Ludox TM40 at $0.40 \% \mathrm{v}$. TM40 data have been multiplied by a factor 10 for clarity.

The scattering length densities of both silica particles were measured by SANS using contrast variation (cf. SI). We obtained an average of $\rho_{\mathrm{Si}}=3.510^{10} \mathrm{~cm}^{-2}$ for SM30 and TM40 particles.

Latex particles: The synthesis and characterization of poly(ethyl methacrylate) (PEMA) latex NPs has been described in detail in ${ }^{40}$. For the deuterated particles the same procedure was adopted. Per-deuterated monomers (purity > 98\%) were purchased from Polymer Source and distilled under 50 mbar prior to polymer synthesis. Here, only the following characteristics are recalled and summarized in Table 1: particle size, chain molecular weights, and scattering length densities. The particle size was controlled by a constant surfactant/monomer mass ratio of 0.21 in the synthesis reactor and measured by dynamic light scattering (DLS) and SAXS. The diameter of the latex particles is comprised between 23 and $29 \mathrm{~nm}$, with a polydispersity of about $20 \%$. Two chain molecular weights were synthetized using different transfer agent (TDM) quantities, and were characterized by gel permeation chromatography (GPC). Using a 0.04 TDM/EMA mass ratio, $17100 \mathrm{~g} / \mathrm{mol}$ polymers were obtained from both H and D monomers. Without TDM, $117200 \mathrm{~g} / \mathrm{mol}$ and $86100 \mathrm{~g} / \mathrm{mol}$ were obtained from $\mathrm{H}$ and $\mathrm{D}$ monomers, respectively. The scattering length densities of the different particles were measured by SANS using contrast variation (cf. SI). 
Table 1. Characteristics of $\mathrm{H}-$ and D-lattices.

\begin{tabular}{|c|c|c|c|c|}
\hline & H-PEMA100 & D-PEMA100 & H-PEMA17 & D-PEMA17 \\
\hline $\mathbf{M}_{\mathbf{w}}(\mathbf{k g} / \mathbf{m o l})$ & 117.7 & 86.1 & 17.1 & 17.1 \\
polydispersity & 1.6 & 1.6 & 1.6 & 1.7 \\
\hline $\boldsymbol{\rho}\left(\mathbf{1 0}^{\mathbf{1 0}} \mathbf{c m}^{-\mathbf{2}}\right)$ & 0.8 & 7.0 & 0.8 & 7.0 \\
\hline $\mathbf{R}_{\text {Latex }}(\mathbf{n m})$ & 11.5 & 11.5 & 13.8 & 14.6 \\
\hline
\end{tabular}

Film formation: Silica-latex nanocomposites have been formed by film formation following the protocol given in ref ${ }^{40}$. To ensure latex beads dissolution and avoid the production of degradation residues, samples were annealed for one week at $120^{\circ} \mathrm{C}$ under vacuum. All samples were prepared using the same H/D volume fraction ratio to fulfill the ZAC conditions: 56/44. NP sizes for the different nanocomposites are given in Table 2. Silica content was measured by thermogravimetric analysis (TGA) after a ramp up to $650{ }^{\circ} \mathrm{C}$ at a rate of $30 \mathrm{~K} / \mathrm{min}$ under nitrogen. Real and nominal values given throughout this article are found in good agreement (see SI). Glass-transition temperatures of $338 \mathrm{~K}$ and $349 \mathrm{~K}$ for the $17 \mathrm{k}$ - and 100k-nanocomposites, respectively, were determined by modulated calorimetry (3 $\mathrm{K} / \mathrm{min}$ ) and were found not to depend on $\Phi_{\mathrm{Si}}$ (see SI).

Table 2. Summary of particles sizes and size ratios in nanocomposites.

\begin{tabular}{|c|c|c|}
\hline & TM40 & SM30 \\
\hline $\mathbf{R}_{\mathbf{S i}}(\mathbf{n m})$ & 14 & 5 \\
$\sigma$ & $11 \%$ & $16 \%$ \\
\hline $\mathbf{R}_{\text {Latex }} / \mathbf{R}_{\mathrm{Si}}$ & 1 & 2.5 \\
\hline
\end{tabular}

Transmission Electronic Microscopy (TEM): Samples were prepared by immersing a thin strip of sample in an epoxy resin (EPON 812) and curing it at $60^{\circ} \mathrm{C}$ for $72 \mathrm{~h}$. After resin polymerization, sections with a nominal thickness of $70 \mathrm{~nm}$ were cut with an ultramicrotome (Leica Ultracut) and placed on TEM grids (Formvar carbon-coated $\mathrm{Cu}$ grids, EMS). Slices were observed with a 1200EX2 Jeol TEM at $100 \mathrm{kV}$. Images were captured with a Quemesa SIS Olympus numerical camera equipped with an 11 Mpixels CCD detector. Representative images as those shown in this article were obtained with a 20000 magnification. 
Small-Angle X-ray Scattering (SAXS): Experiments were performed on beamline ID2 at the European Synchrotron Radiation Facility (ESRF, Grenoble France) at a wavelength $\lambda$ of $1 \AA$ with a sample to detector distance D of $2.5 \mathrm{~m}$, yielding a total q-range from 0.001 to $0.15 \AA^{-1}$. The scattering cross section per unit sample volume $\mathrm{d} \Sigma / \mathrm{d} \Omega\left(\mathrm{in}^{-1}\right)$, which we term scattered intensity I(q), was obtained by using standard procedures including background subtraction and calibration given by ESRF. A technical point concerns the subtraction of the pure polymer matrix background which is difficult due to heterogeneous sample thicknesses. Our procedure is to subtract a weighted matrix intensity such that the form factor oscillations of the NPs after subtraction match the independently measured pure form factor (Figure 1). See ref ${ }^{40}$ for details.

Small-Angle Neutron Scattering (SANS): Experiments were performed on two instruments: KWS2 operated by JCNS at the Heinz Maier-Leibnitz Zentrum (MLZ, Garching Germany), and D11 at the Institut Laue Langevin (ILL, Grenoble France), using different configurations covering a q-range from ca. $1.310^{-3}$ to $0.28 \AA^{-1}$. D11: D = $34 \mathrm{~m} ; \mathrm{D}=8 \mathrm{~m}$; and D $=1.75 \mathrm{~m}$, all $\lambda=8 \AA$, and KWS2: $\mathrm{D}=20 \mathrm{~m}, \lambda=10 \AA$; D $=8 \mathrm{~m}, \lambda=6 \AA$; and $\mathrm{D}=2 \mathrm{~m}, \lambda=6 \AA$. Empty cell or empty beam subtraction, calibration by $1 \mathrm{~mm}$ light water in Hellma cuvettes, and absolute determination of scattering cross sections $\mathrm{I}(\mathrm{q})=\mathrm{d} \Sigma / \mathrm{d} \Omega$ per unit sample volume in $\mathrm{cm}^{-1}$ were performed using standard procedures ${ }^{42}$. Incoherent background was estimated using a far-point method and compatible with the high-q scattering laws of polymer conformations. The reduction of raw data including corrections for detector sensitivity and background noise was performed by the routines qtiKWS ${ }^{43}$ and Lamp ${ }^{44}$, for KWS2 and D11 data respectively.

The latex scattering length density was determined by independent contrast variation experiments: $\rho_{\mathrm{H}}=0.8 \times 10^{10} \mathrm{~cm}^{-2}$ (resp. $\rho_{\mathrm{D}}=7.0 \times 10^{10} \mathrm{~cm}^{-2}$ ), in agreement with the macroscopic density and the composition. The scattering length density of the H/D-matrix is then given by $\rho_{\mathrm{HD}}=\Phi_{\mathrm{H}} \rho_{\mathrm{H}}+\Phi_{\mathrm{D}} \rho_{\mathrm{D}}$, and if the silica scattering length density $\rho_{\mathrm{Si}}$ matches the average of the polymer mixture, $\rho_{\mathrm{Si}}=\rho_{\mathrm{HD}}$, then the zero average contrast condition is fulfilled. The index-match point of the silica nanoparticles is thereby found to be at a matrix volume fraction in hydrogenated polymer of $\Phi_{\mathrm{H}}=56 \%\left(\Phi_{\mathrm{H}}+\Phi_{\mathrm{D}}=100 \%\right)$. 


\section{Results and discussion}

\section{Structure of silica NPs in nanocomposites studied by SAXS and TEM}

The structure of the silica filler for one of the four systems has been investigated before ${ }^{40}$. We will see shortly that for the analysis of the chain structure, the silica signal is also needed, which is why the dispersion state of both silica NPs in latex matrices of $17 \mathrm{~kg} / \mathrm{mol}$ and 100 $\mathrm{kg} / \mathrm{mol}$ was also investigated by SAXS. The results for intensities after subtraction of the matrix contribution are plotted in Figure 2. The matrix chains are a mixture of H- and Dpolymer for the subsequent studies of chain conformations under ZAC in the same samples by SANS below (without any effect on the silica-matrix contrast in SAXS). It is the aim of SANS-ZAC experiments to highlight the polymer by cancelling the contribution of the silica, which is also why they are measured by SAXS here. 

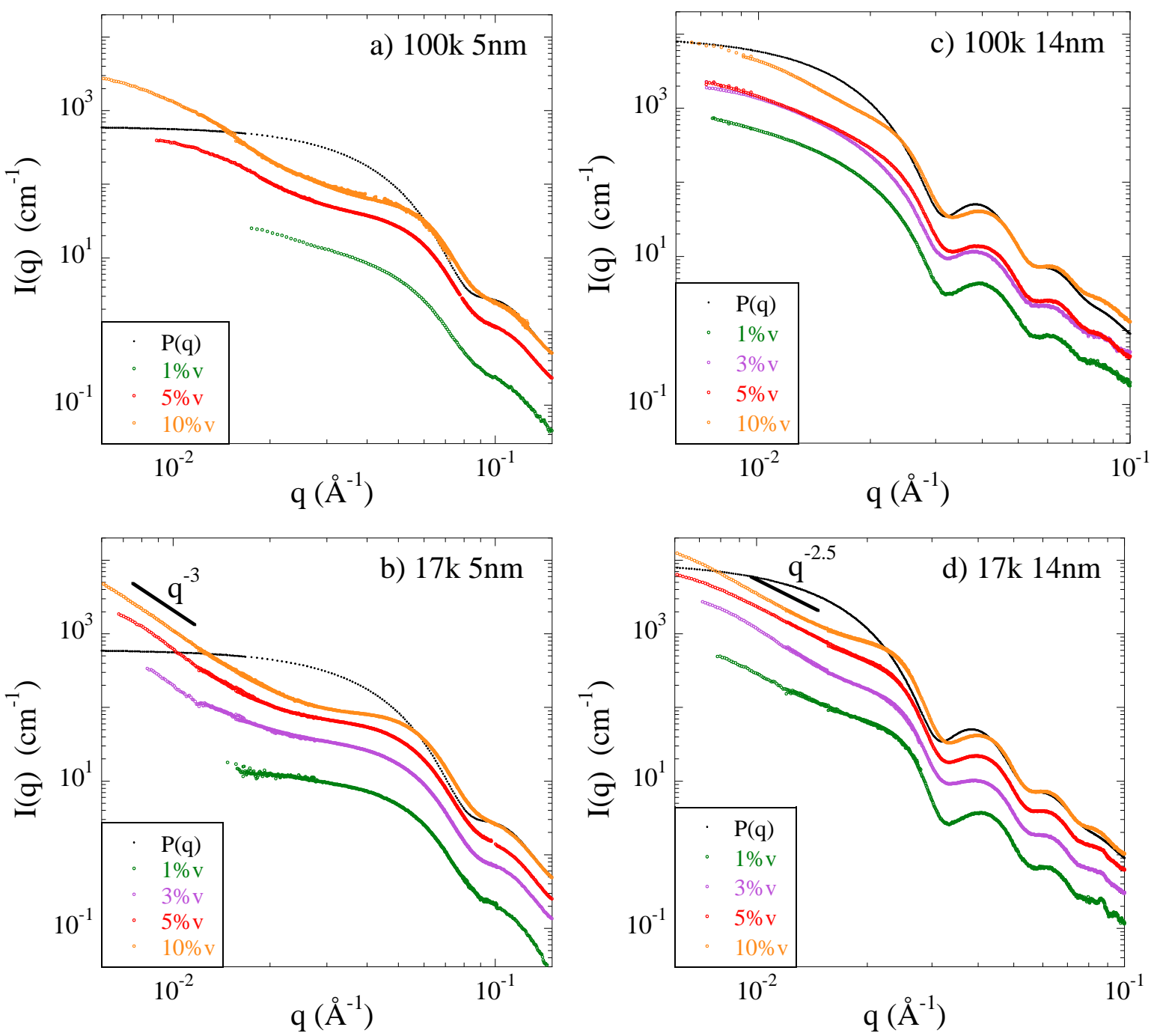

Figure 2. SAXS intensities of four concentration series of silica-latex nanocomposites (silica volume fraction: $0<\Phi_{\mathrm{Si}}<10 \% \mathrm{v}$ ), for two polymer molecular weights and silica particles sizes: (a) 100 $\mathrm{kg} / \mathrm{mol}, 5 \mathrm{~nm}$ (b) $17 \mathrm{~kg} / \mathrm{mol}, 5 \mathrm{~nm}$ (c) $100 \mathrm{~kg} / \mathrm{mol}, 14 \mathrm{~nm}$ (d) $17 \mathrm{~kg} / \mathrm{mol}, 14 \mathrm{~nm}$. The matrix is a 56/44 $(\mathrm{v} / \mathrm{v})$ mixture of $\mathrm{H}$ and $\mathrm{D}$ polymer of same molecular weight. The respective silica form factors, $\mathrm{P}(\mathrm{q})$, are superimposed to the $10 \% \mathrm{v}$ nanocomposites.

The SAXS curves display the same features as a function of concentration for small and big silica NPs. In Figures 2c and 2d, for example, the prominent oscillations due to the form factor of the well-defined TM40 spheres are visible in the high-q range. The same is true for all other graphs, with a damped form factor oscillation for the smaller SM30 NPs in Figures $2 \mathrm{a}$ and $2 \mathrm{~b}$, indicating higher polydispersity (Table 2 ). For comparison, a form factor has been superimposed to the highest concentrations in each graph. The interesting part of the intensity curves is the intermediate- and low-q range, where the signature of interacting NP aggregates 
is found, causing deviations from the form factor. Aggregation results in an increase in the low-q scattering, which can sometimes be described by a power law representing a fractal dimension ( $\mathrm{d}_{\mathrm{f}}$ between 2.5 and 3 ) for the low-mass nanocomposites, as indicated in Figure 2. Only in Figure 2c, aggregation is rather limited, as one can deduce from the weak deviations between the NP form factor and the nanocomposite intensity. In conclusion, the bigger silica beads appear to be rather well dispersed in presence of the longest chains, whereas some aggregation is present in all other cases.

For comparison, the structure of the silica aggregates and their dispersion has also been studied in real space by TEM. Typical pictures are shown in Figure 3 for the same samples as before, at a fixed silica volume fraction of $3 \% \mathrm{v}$. The best dispersion is observed in Figure $3 \mathrm{c}$ (big NPs, long chains), and particle shapes are also better defined for the bigger NPs (Fig.3c and 3d). In all other cases, some aggregation is found. As discussed in our previous article ${ }^{40}$, the low viscosity of the shorter polymer chains favors aggregation during annealing of samples, and the NPs in Figure 2b (resp. 2d) are more aggregated than in $2 \mathrm{a}$ (resp. 2c). However, unlike with the bigger NPs, aggregation is also observed for the small NPs in the high viscosity matrix, Figure 2a. First of all, the smaller silica beads are pre-aggregated as a starting point of sample formation (see materials section). Moreover, aggregation may be due to a higher mobility of smaller NPs, as well as to the smaller interparticle distances of smaller NPs at fixed volume fraction, which is three times smaller for the smaller beads. This geometrical factor allows diffusion processes to cover distances necessary for collision and aggregation during annealing about ten times faster. Altogether a speed up by a factor of about 30 is thus obtained for the smaller beads, and this appears to be sufficient to induce some aggregation even with the high viscosity polymer matrix. If, in addition to this, the low viscosity polymer is used for the matrix, then another factor of 200 favoring aggregation is introduced, in agreement with aggregation observed in Figures $3 \mathrm{~b}$ and $\mathrm{d}$. 

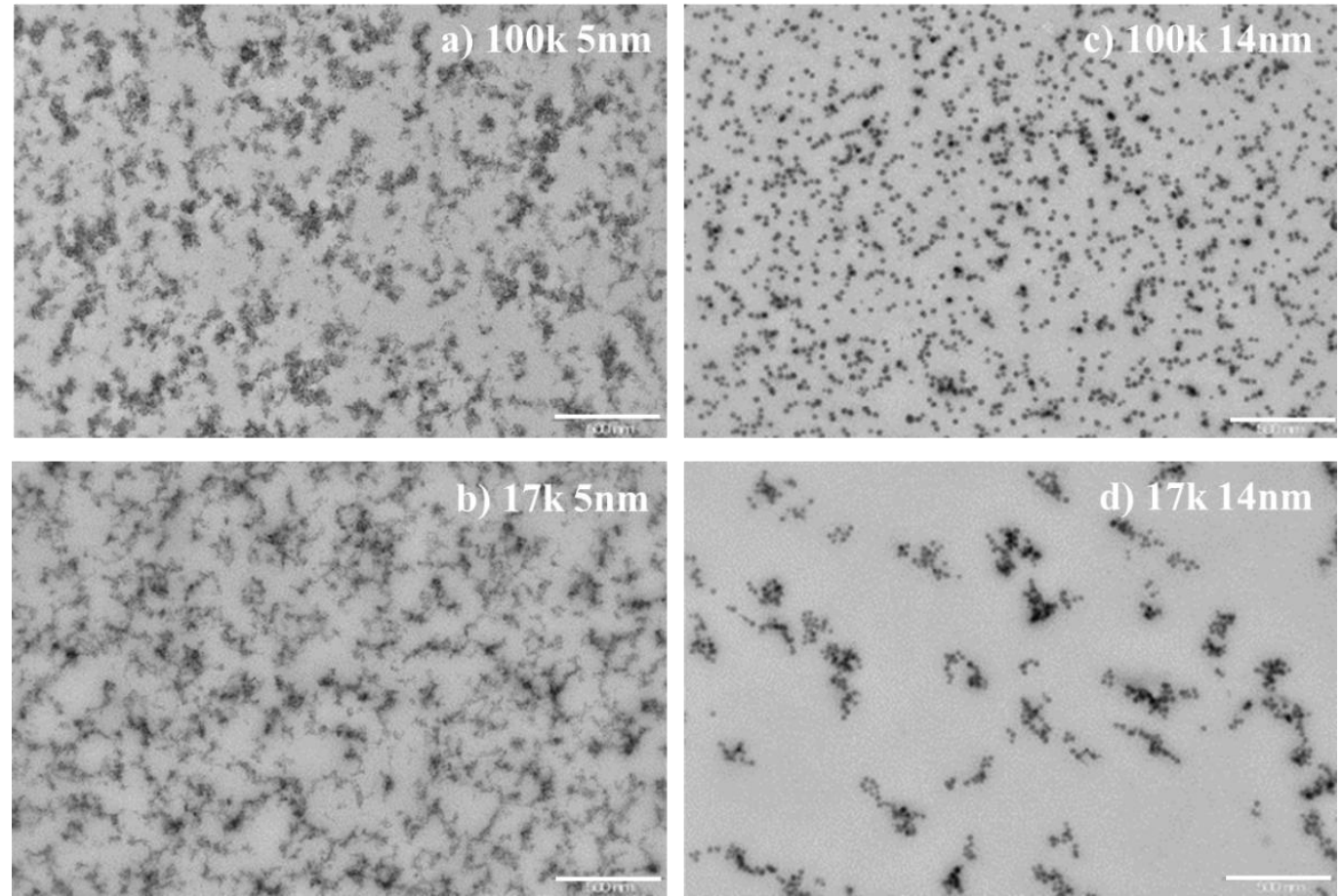

Figure 3. TEM pictures of $\Phi_{\mathrm{Si}}=3 \% \mathrm{v}$ silica-latex nanocomposites for two polymer molecular weights and silica particles sizes. (a) $100 \mathrm{~kg} / \mathrm{mol}, 5 \mathrm{~nm}$, (b) $17 \mathrm{~kg} / \mathrm{mol}, 5 \mathrm{~nm}$, (c) $100 \mathrm{~kg} / \mathrm{mol}, 14 \mathrm{~nm}$, and (d) $17 \mathrm{~kg} / \mathrm{mol}, 14 \mathrm{~nm}$. Scale bar: $500 \mathrm{~nm}$.

\section{Chain structure in nanocomposites by SANS}

The chain structure in nanocomposites was studied using SANS and ZAC as described in the materials section, varying the silica volume fraction, for the four series with different silica bead sizes and polymer masses. The results are shown in Figure 4: small silica NPs on the left, big ones on the right, and long chains on top, short ones below. 

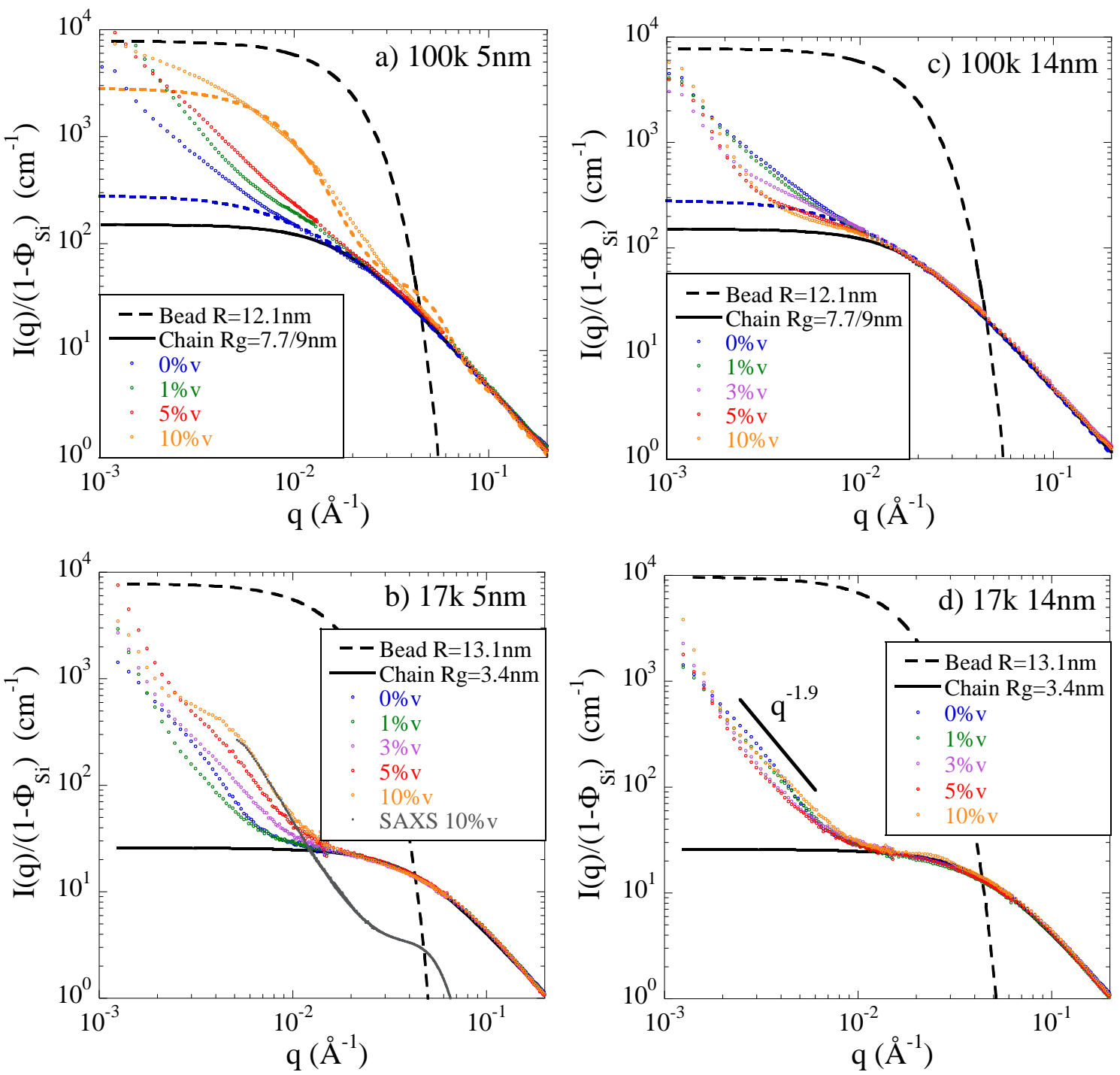

Figure 4. SANS intensities of the four silica volume fraction series of nanocomposites with ZAC. (a) $100 \mathrm{~kg} / \mathrm{mol}, 5 \mathrm{~nm}$ (b) $17 \mathrm{~kg} / \mathrm{mol}, 5 \mathrm{~nm}$ (c) $100 \mathrm{~kg} / \mathrm{mol}, 14 \mathrm{~nm}$ (d) $17 \mathrm{~kg} / \mathrm{mol}, 14 \mathrm{~nm}$. The full dark line is the calculated polymer chain signal and the dashed line is the Guinier function describing the initial latex beads. Dotted lines are the Pedersen models with $\alpha=86 \%$ (matrix, blue) in a) and c), and $\alpha=40 \%$ bead dissolution (10\%v silica, orange) in a). In b), the grey line corresponds to the $10 \% \mathrm{v}$ nanocomposite SAXS spectra (arbitrarily) superimposed to the SANS spectra.

In Figure 4, the scattering of the two polymer matrices is shown ( $0 \%$ silica), for $17 \mathrm{~kg} / \mathrm{mol}$ and $100 \mathrm{~kg} / \mathrm{mol}$. At low q, the intensities are found to increase, and are much higher than H/D concentration fluctuations described by the Random Phase Approximation (RPA) ${ }^{45}$. For long chains, parts of this upturn can be explained by incomplete latex bead dissolution using the Pedersen model for block copolymer micelles ${ }^{46,47}$, which we have adapted to hairy beads previously for a similar silica-polyacrylate latex system ${ }^{24}$. In order to relate this contribution 
to the origin of hairy beads, the small-angle scattering of initial latex beads as calculated from contrast and radius and described by a Guinier law is also plotted in Figures 4 a-d. This function is much more intense at small angles than all other observed intensities, which is due to the fact that the beads contain initially many chains $(\approx 50$ for $100 \mathrm{~kg} / \mathrm{mol}, \approx 300$ for 17 $\mathrm{kg} / \mathrm{mol}$, respectively). During film formation, the latex beads are dissolved in the matrix, i.e., their chains escape progressively. This dissolution depends on the chain mass, short chains forming a low-viscosity matrix favoring interdiffusion. The process leads to the formation of hairy beads of smaller mass than the initial bead, and thus reduced low-q intensity, which results in a latex bead dissolution parameter of $86 \%$ (see dotted line in Figure 4a). In the 17kmatrix case (Figures $4 \mathrm{~b}$ or $4 \mathrm{~d}$ ), this contribution is negligible due to the low matrix viscosity favoring chain interdiffusion. The additional low-q increase of the matrices (below $710^{-3} \AA^{-1}$ ), however, proved to be incompatible with the Pedersen model, and must be attributed to nanobubbles or other large-scale heterogeneities ${ }^{32}$. At intermediate and large angles, both matrices display intensities typical for Gaussian chains $\left(\mathrm{q}^{-2}\right.$ power law at high $\left.\mathrm{q}\right)$, and they are described by a single Debye function ${ }^{48}$ for the $17 \mathrm{~kg} / \mathrm{mol}$ matrix, and as the combination ${ }^{20,24}$ of two contributions for the $100 \mathrm{~kg} / \mathrm{mol}$ latex (Table 1). Finally, this description of the polymer form factor yields the determination of the chain radius of gyration characterizing the polymer conformation. The small chains $(17 \mathrm{~kg} / \mathrm{mol})$ are described with $\mathrm{R}_{\mathrm{g}}=3.4 \mathrm{~nm}$, with an error bar of $0.2 \mathrm{~nm}$ as obtained from the spread of the fit values for the different silica fractions. For the bigger chains, $\mathrm{R}_{\mathrm{g}}$ equals $9.0 \pm 1.0$ and $7.7 \pm 1.0 \mathrm{~nm}$, for 117 and $86 \mathrm{~kg} / \mathrm{mol}$, respectively. In this case, due to the additional hairy bead contribution, the radius of gyration cannot be extracted directly. The error bar corresponds to the range of values compatible with the global model. Consistently, the relationship between $R_{\mathrm{g}}$ and the molecular mass is in agreement with Gaussian statistics $\left(\mathrm{R}_{\mathrm{g}} \propto \mathrm{M}_{\mathrm{w}}{ }^{0.51}\right.$ from our data).

Upon addition of silica, the scattered intensities obey the same high-q power law in Figure 4 a-d indicating that chains keep their Gaussian conformation, independently of silica volume fraction, and whatever the ratio $\mathrm{R}_{\mathrm{Si}} / \mathrm{R}_{\mathrm{g}}$. The radius of gyration is found to be identical to the matrix value for the short chains, as can be seen in the Guinier regime $\left(\mathrm{q} \approx 310^{-2} \AA^{-1}\right)$ in Figures $4 \mathrm{~b}$ and $4 \mathrm{~d}$. For the longer chains, other contributions are superimposed to the scattering and will be described below. In all cases, however, the matrix values for $R_{\mathrm{g}}$ were kept fixed in the data treatment discussed below (Pedersen model), and the corresponding chain contribution was found compatible with the scattering data of nanocomposites. Note that this measurement of the chain size in nanocomposites was the main motivation for 
performing these ZAC-SANS experiments, and it has triggered research over the past 15 years ${ }^{22-33}$, with limitations as discussed in the next section. Indeed, at q below ca. $10^{-2} \AA^{-1}$, the SANS intensities grow, in a different manner depending on polymer mass, and silica NP size and concentration. We start with discussing Figure 4d (big NPs, short chains). Apart from minor deviations, the low-q increase here follows a power law $\left(\mathrm{q}^{-1.9}\right)$ and is independent of $\Phi_{\mathrm{Si}}-$ it is thus not related to the filler. Note that scattering from the pure H PEMA matrix measured in ${ }^{40}$ displays a similar upturn, indicating that it is not due to H/D demixing as observed by Crawford et al $^{33}$. Its origin is thus most probably the same as for the pure matrix as described by Winey et al ${ }^{32}$ - voids and defects -, and is present at very small angles for other polymer/particle couples. Incidentally, the fact that the curves in Figure $4 \mathrm{~d}$ superimpose so well for different $\Phi_{\text {Si }}$ proves that ZAC conditions were fulfilled rather precisely.

For long polymer chains and big NPs (Figure 4c), the low-q scattering actually decreases as silica is added, and intensities are higher than in Figure 4d. This confirms that silica is not visible for the case of large filler NPs, and indicates that the higher chain mass is responsible for the intensity increase. At low silica fraction, the shape of the curve in Figure $4 \mathrm{c}$ can be described like the matrix by the same Pedersen model of hairy beads (see dotted line, $\alpha=$ $86 \%$ ). At high $\Phi_{\mathrm{Si}}$, latex bead dissolution tends towards $100 \%$, and a baseline presumably due to defects similar to Figure $4 \mathrm{~d}$ is recovered. Big filler NPs thus seem to favor latex dissolution.

On the contrary, long chains with small silica beads (Figure 4a) show a systematic intensity increase with $\Phi_{\mathrm{Si}}$, which is also well described by a Pedersen model as shown in Figure 4a for the $10 \% \mathrm{v}$-nanocomposite, indicating incomplete latex dissolution up to only $\alpha=40 \%$ (1\%v: $80 \%, 5 \%$ v: $75 \%$, see SI). Unfortunately, dissolution is thus less advanced in presence of filler as previously observed ${ }^{24}$, but stronger annealing was not attempted to avoid degradation issues. From a comparison of evolution with small and big NPs in Figure 4a and 4c, respectively, the surprising result of apparently higher chain mobility - and thus higher bead dissolution - in presence of the larger silica NPs is found.

For small NPs and short chains (Figure 4b), scattering intensities display distinct deviations in shape, with a silica-dependent growth of a shoulder around $0.005 \AA^{-1}$. Similarities with the silica scattering discussed in Figure 2 and reproduced here ("SAXS 10\%v") suggest that, in this case, the silica is visible, in spite of all our efforts to match this component. In the next section, an explanation including a quantitative model will be proposed for this case. Note 
that in the 100k-case, the longer chains induce a substantially higher scattering signal (due to their form factor) than the $17 \mathrm{k}$-nanocomposites, and cover any contribution from the silica beads.

To summarize, the supposedly matched silica contribution in ZAC is indeed well suppressed in the case of big filler NPs or long chains, but clearly visible for the small NPs with short chains: it follows that under these conditions size matters even for contrast, which is sizeindependent by definition! Secondly, incomplete latex sphere dissolution can be described by a Pedersen model for long chains, as already recognized before ${ }^{24}$. Dissolution is slower for the more viscous samples based on longer matrix chains, and depends on the NP size.

\section{A model for scattering due to contrast-matched silica nanoparticles}

Several authors have performed ZAC-SANS experiments in the past and have reported the observation of silica contributions in spite of careful contrast matching $22,23,25,28,29,33$. Some of them have invoked specific interactions between filler particles and $\mathrm{H}$ - or D-polymer, favoring preferential adsorption of one or the other, but none has tempted a quantitative evaluation of the unwanted filler contribution. Here we propose a mechanism based on local H/D deviations in silica-latex nanocomposites, which explain the visibility of silica in the different cases in Figure 4, and set up a quantitative model for fitting the observed contributions, with a single free parameter.

If the immediate polymer environment of NPs is for some reason unbalanced, in the sense that the local H/D-ratio does not equal the global one, a detectable polymer shell is created, see Figure 5 for illustration. The inner side of the shell is defined by the NPs, thus evidencing their shape, and ruining the polymer contribution to scattering. Due to the absence of correlations between the polymer shell and the chain form factor, the total scattered intensity can be written as a sum of these two contributions:

$$
\mathrm{I}_{\text {Tot }}(\mathrm{q})=\left(1-\Phi_{\mathrm{Si}}\right) \mathrm{I}_{\text {Chain }}(\mathrm{q})+\mathrm{I}_{\text {Shell }}(\mathrm{q})
$$

where $\mathrm{I}_{\text {Chain }}(\mathrm{q})$ is the classical Debye law, i.e., the function describing the desired polymer conformation. It also takes into account chain scattering of polymer forming the shell, and possibly contains another additive Pedersen-type contribution in case of partial latex dissolution ${ }^{24}$. Note that the addition of contributions in eq.(1) was already anticipated by 
Botti et al, who determined an empirical prefactor of the silica contribution expressed by $\mathrm{I}_{\text {Shell }}$ in our approach ${ }^{29}$. The (unwanted) scattering of the shell reads:

$$
\mathrm{I}_{\text {Shell }}(\mathrm{q})=\left.\frac{\mathrm{n}}{\mathrm{v}}\right|_{\text {Silica }} \Delta \rho_{\text {Shell }}^{2} \mathrm{~V}_{\text {Shell }}^{2} \mathrm{P}_{\text {Shell }}\left(\mathrm{q}, \mathrm{R}_{\mathrm{Si}}, \mathrm{d}\right) \mathrm{S}(\mathrm{q})
$$

where the shell number density $\mathrm{n} / \mathrm{V}$ is equal to the one of the silica NPs which can be replaced by $\Phi_{\mathrm{Si}} / \mathrm{V}_{\mathrm{Si}}\left(\mathrm{V}_{\mathrm{Si}}\right.$ is the volume of a silica NP), and the average contrast $\Delta \rho_{\text {Shell }}$ of the H- and Drich zones surrounding the NP will be evaluated below. $\mathrm{P}_{\text {Shell }}$ is the normalized form factor of the homogeneous shell. Note that the geometry of the shell is well-defined on the inner side, but the presumably fuzzy outer interface is only approximately described by $\mathrm{P}_{\text {Shell. }}$. For thin shells, the shell volume is given by $\mathrm{V}_{\text {Shell }}=4 \pi \mathrm{R}_{\mathrm{Si}}{ }^{2} \mathrm{~d}$, where $\mathrm{d}$ is the shell thickness. From the experimental results - the superposition in Figure $4 \mathrm{~b}$ - one may assume shells to be thin, because otherwise the shape of the embedded silica could not be observed in the scattering. Indeed, the internal contribution of too big a shell would be negligible. The structure factor between shells $\mathrm{S}(\mathrm{q})$ is identical to the one between silica NPs, because the shells stick to the NPs. This allows us to retrieve the structure factor from the silica scattering measured by an independent SAXS experiment, which is sensitive only to SAXS particle contrast $\Delta \rho_{\text {Si. }}$. It can be written as:

$$
\mathrm{I}_{\mathrm{Si}}(\mathrm{q})=\Phi_{\mathrm{Si}} \Delta \rho_{\mathrm{Si}}^{2} \mathrm{~V}_{\mathrm{Si}} \mathrm{P}_{\mathrm{Si}}(\mathrm{q}) \mathrm{S}(\mathrm{q})
$$

Solving eq. (3) for $\mathrm{S}(\mathrm{q})$ and replacing in eqs. (2) and (1) yields the total scattering as a function of the silica measured by SAXS and the unknown shell prefactor given by the product of shell contrast $\Delta \rho_{\text {Shell }}$ and thickness d. It is thus possible to fit the silica contribution via its prefactor, and determine $\mathrm{d} \times \Delta \rho_{\text {Shell. }}$. We now propose a statistical model for the shell contrast, allowing finally a determination of $\mathrm{d}$. 


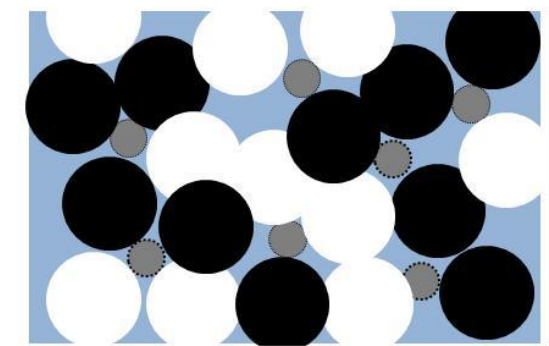

(a)

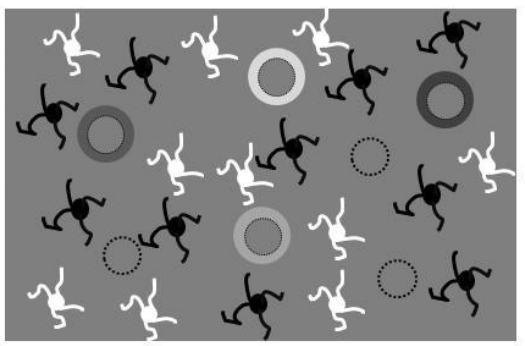

(b)

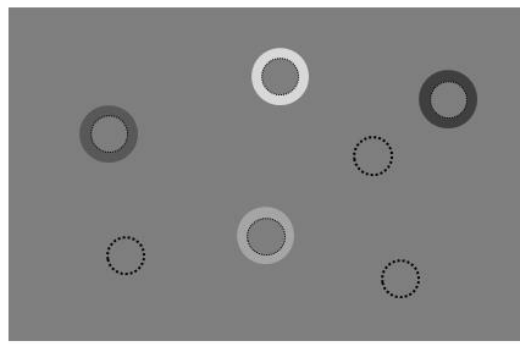

(c)

Figure 5. Sketch of the model. (a) Before latex bead dissolution, the color representing scattering length density. Highly concentrated suspension in water (blue) of $\mathrm{H}$ - and D-latex beads (in white, resp. black), with silica (grey) surrounded by a variable ratio of $\mathrm{H}$ and $\mathrm{D}$ beads. (b) Partial latex dissolution represented by hairy beads. Well-dissolved $\mathrm{H}$ and $\mathrm{D}$ polymer chain form a matrix matching the silica scattering length density. Chains in interaction with silica form a shell, the scattering length density of which depends on the original silica environment. (c) Total dissolution of latex. The remaining contrast is due the unmatched polymer shells caused by the initial statistical heterogeneities.

In our model, the mismatch of the H/D-ratio is explained by the statistical properties of the local polymer environment of each NP, allowing the determination of $\Delta \rho_{\text {Shell }}$. For the sake of simplicity of the argument, the silica beads are thought to be individually dispersed. Our hypothesis is that the H/D-mismatch is due to a statistical local dissymmetry caused by the small number of latex beads defining the first layer of the environment of a silica bead. This mismatch is conserved due to the reduced mobility of polymer chains close to the silica interface $^{12,14,49}$, which may be caused by attractive interactions between polar groups of PEMA and hydroxyl groups on the surface of silica particles ${ }^{50}$. It is interesting to compare the conservation of the ZAC mismatch observed here to our previous results ${ }^{24}$. In the latter case, the combination of lower matrix $\mathrm{T}_{\mathrm{g}}$ and stronger annealing without degradation led to fulfillment of the ZAC condition. Note that for the low silica volume fractions used here, no systematic modification of the glass transition was found by DSC (see SI), as observed by Moll et al ${ }^{51}$. The number of latex beads surrounding a given silica bead - the coordination number - depends primarily on the ratio of the radii $\mathrm{R}_{\mathrm{Si}} / \mathrm{R}_{\mathrm{La}}$. A simple estimation based on a local square arrangement on the sphere containing the latex centers is given by:

$$
\mathrm{N}=\frac{4 \pi\left(\mathrm{R}_{\mathrm{Si}}+\mathrm{R}_{\mathrm{La}}\right)^{2}}{\left(2 \mathrm{R}_{\mathrm{La}}\right)^{2}}=\pi\left(1+\frac{\mathrm{R}_{\mathrm{Si}}}{\mathrm{R}_{\mathrm{La}}}\right)^{2}
$$


For $\mathrm{R}_{\mathrm{Si}}$ and $\mathrm{R}_{\mathrm{La}}$ of the same order of magnitude, $\mathrm{N}$ is a rather small number; in particular, $\mathrm{N} \approx$ $12-13$ for NPs of the same size, which is the case of the nanocomposites prepared with 14 $\mathrm{nm}$ silica. For a much smaller central silica bead with $\mathrm{R}_{\mathrm{Si}}=5 \mathrm{~nm}$, one obtains an even lower number of neighbors, $\mathrm{N} \approx 6$. The point of the present argument is that even if the ZAC condition is on average fulfilled, this may not be the case locally due to fluctuations, which are of higher relative importance for small N. Defining arbitrarily the first shell of latex beads as the contrast defining neighborhood, the local contrast between a given silica NP and its environment can be written as the following contrast of a shell:

$$
\Delta \rho_{\text {loc }}=\left[\frac{\mathrm{n}_{\mathrm{H}}}{\mathrm{N}} \rho_{\mathrm{H}}+\frac{\mathrm{n}_{\mathrm{D}}}{\mathrm{N}} \rho_{\mathrm{D}}\right]-\rho_{\mathrm{Si}}
$$

where $\mathrm{n}_{\mathrm{H}}$ is the number of H-beads, $\mathrm{n}_{\mathrm{D}}$ the one of D-beads, with $\mathrm{n}_{\mathrm{H}}+\mathrm{n}_{\mathrm{D}}=\mathrm{N}$. Obviously, if the local fractions $n_{i} / N$ equal the overall proportion $\Phi_{i}$, then $\Delta \rho_{\text {loc }}$ is equal to zero, and the shell and thus the silica NPs are invisible. Introducing the contrast between H and D beads $\Delta \rho_{\mathrm{HD}}=\rho_{\mathrm{D}}-\rho_{\mathrm{H}}$, eq.(5) can be rewritten to make this concept clear:

$$
\Delta \rho_{\text {loc }}=\left[\Phi_{\mathrm{H}}-\frac{\mathrm{n}_{\mathrm{H}}}{\mathrm{N}}\right] \Delta \rho_{\mathrm{HD}}
$$

The intensity apparently scattered by the silica NPs is due to the scattering of the local shell which carries H/D-contrast, whereas the silica NPs are matched by the average contrast of the matrix. The next step is to calculate the scattering cross section of these contrast-carrying shells surrounding all the silica NPs in a sample. If the contrast is averaged first, and then squared in order to obtain the prefactor of the intensity, it follows by volume conservation $\left\langle\mathrm{n}_{\mathrm{H}} / \mathrm{N}\right\rangle=\Phi_{\mathrm{H}}$, and $\mathrm{I}(\mathrm{q})$ due to silica (i.e., shells) becomes zero. This can be looked at as a "coherent" contribution. If however each scattering contribution from shells around individual nanoparticles is independent of the others, then an "incoherent" contribution comes into play. Formally, it may be written as the sum of the squares of the contributions of shells of each NP, or alternatively as the sum over the squares of the contributions of different configurations (defined by $\mathrm{n}_{\mathrm{H}}^{\mathrm{i}}$ ) weighted by the corresponding probability of occurrence $p\left(n_{H}{ }^{i}\right)$. The resulting shell contrast is then given by the average of the squares of the local contrasts: 


$$
\Delta \rho_{\text {Shell }}^{2}=\sum_{\mathrm{n}_{\mathrm{H}}^{\mathrm{i}}=0}^{\mathrm{N}} \mathrm{p}\left(\mathrm{n}_{\mathrm{H}}^{\mathrm{i}}\right) \Delta \rho_{\text {loc }}^{2}\left(\mathrm{n}_{\mathrm{H}}^{\mathrm{i}}\right)
$$

where the binomial distribution is given by:

$$
\mathrm{p}\left(\mathrm{n}_{\mathrm{H}}^{\mathrm{i}}\right)=\left(\begin{array}{c}
\mathrm{N} \\
\mathrm{n}_{\mathrm{H}}^{\mathrm{i}}
\end{array}\right) \Phi_{\mathrm{H}}^{\mathrm{n}_{\mathrm{H}}^{\mathrm{i}}} \Phi_{\mathrm{D}}^{\mathrm{n}_{\mathrm{D}}^{\mathrm{i}}}
$$

The calculation of the shell contrast using the expectation value and the variance of $p$ is straightforward and gives:

$$
\Delta \rho_{\text {Shell }}^{2}=\frac{1}{N} \Phi_{H}\left(1-\Phi_{H}\right) \Delta \rho_{\mathrm{HD}}^{2}
$$

Combining eq.(9) with eqs. (2) and (3), we obtain the following final result:

$$
\mathrm{I}_{\text {Shell }}(\mathrm{q})=9 \mathrm{I}_{\mathrm{Si}}(\mathrm{q}) \frac{\Phi_{\mathrm{H}} \Phi_{\mathrm{D}}}{\mathrm{N}}\left(\frac{\Delta \rho_{\mathrm{HD}}}{\Delta \rho_{\mathrm{Si}}}\right)^{2}\left(\frac{\mathrm{d}}{\mathrm{R}_{\mathrm{Si}}}\right)^{2} \frac{\mathrm{P}_{\text {Shell }}(\mathrm{q})}{\mathrm{P}_{\mathrm{Si}}(\mathrm{q})}=\mathrm{K} \frac{\mathrm{P}_{\text {Shell }}(\mathrm{q})}{\mathrm{P}_{\mathrm{Si}}(\mathrm{q})} \mathrm{I}_{\mathrm{Si}}(\mathrm{q})
$$

where $\mathrm{d}$, the thickness of the shell, is the only free parameter. Note that the normalized form factors $P_{S i}(q)$ and $P_{\text {Shell }}(q)$ tends to 1 at sufficiently small angles, which is the case below $q \approx$ $10^{-2} \AA^{-1}$ where the silica contributes. In this range, only the parameter $\mathrm{K}$ is thus of importance for fitting. In the intermediate-q regime, the ratio of the form factors $\mathrm{P}_{\text {Shell }}(\mathrm{q}) / \mathrm{P}_{\mathrm{Si}}(\mathrm{q})$ decreases to below one because of the larger size of the shell with respect to the silica core, and in the quantitative treatment below this is accounted for via the ratio of the corresponding Guinier expressions $\exp \left[-\mathrm{q}^{2}\left(\mathrm{R}_{\mathrm{g}, \text { Shell }}{ }^{2} / 3-\mathrm{R}_{\mathrm{Si}}{ }^{2} / 5\right)\right]$, where $\mathrm{R}_{\mathrm{g} \text {,Shell }}$ is the radius of gyration of the shell. At high-q, finally, the ratio reaches a plateau value related to the ratio of the specific surfaces, which is not of interest due to the negligible contribution of silica in this q-range. The size of the silica NPs enters eq.(10) via $\mathrm{N}$ and $\mathrm{R}_{\mathrm{Si}}$, which introduces a strong dependence of the visible silica contribution on particle size. This size dependence is illustrated in Figure 6, where the prefactor $\mathrm{K}$ in eq.(10) is plotted for various shell thicknesses $\mathrm{d}$. 


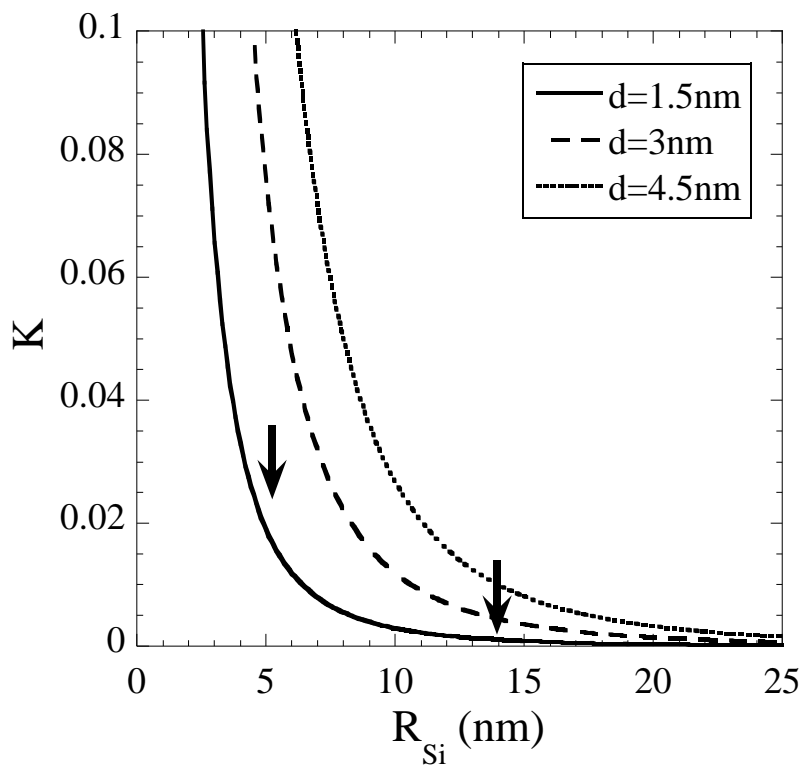

Figure 6. Evolution of the silica scattering prefactor $\mathrm{K}$ as function of silica radius $\mathrm{R}_{\mathrm{Si}}$, for several shell thicknesses $\mathrm{d}$, in a system characterized by latex particles of radius $14 \mathrm{~nm}$. Arrows indicate the prefactor for the two silica NPs used in this study.

To summarize, the intensity scattered by the shell surrounding the silica NPs can be deduced from the number of neighboring latex beads $\mathrm{N}$, which itself depends on the size ratio $\mathrm{R}_{\mathrm{Si}} / \mathrm{R}_{\mathrm{La}}$, and from the silica scattering function. Due to the dependence on $\mathrm{R}_{\mathrm{Si}}$, this contribution tends to be negligible for bigger NPs, as observed indeed in our experimental results in Figure 4 (left vs. right), where a decrease by a factor of 17 is expected between the smaller and the larger NPs. This dependence is also indicated by the arrows in Figure 6.

The application of the model to the results for small silica NPs and small chains leads to fits of the total scattered intensity including the silica contribution as shown in Figure 7 a for a silica fraction of $10 \% \mathrm{v}$. The fit is of rather good quality, and the prefactor in front of $\mathrm{I}_{\mathrm{Si}}(\mathrm{q})$ in eq.(10) is found to be 0.02 . This leads to a shell thickness of $1.6 \mathrm{~nm}$, a reasonable value given the size of the latex beads. The same prefactor is obtained for all silica volume fractions (see SI) indicating a constant thickness of the shell. Figure 7a thus shows that it is possible to understand the origin of the silica scattering, and in particular its amplitude, from geometrical considerations based on the sizes of the silica and the latex nanoparticles. 

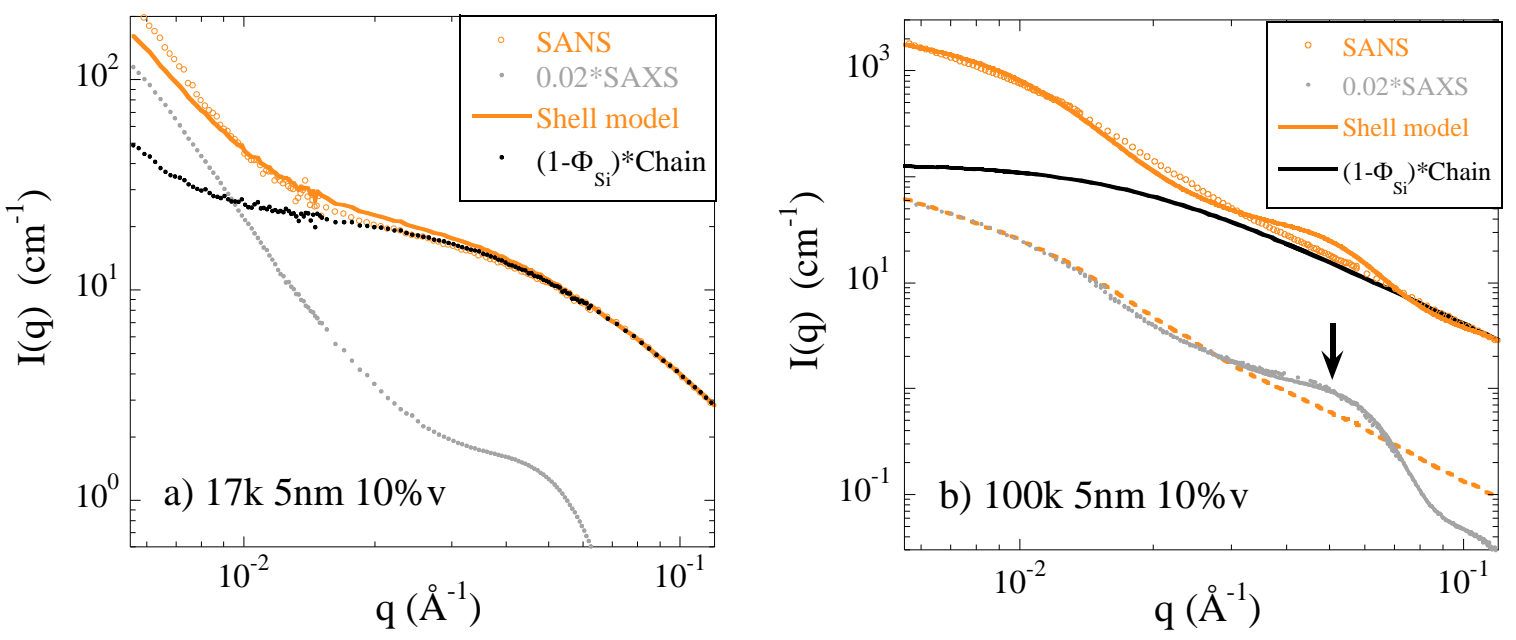

Figure 7. (a) Comparison of the SANS intensity of the $10 \%$ v-nanocomposite (short chains, small NPs) with a linear combination of the experimental chain signal and the silica contribution following the shell model explained in the text. (b) Comparison of the SANS intensity of the $10 \% \mathrm{v}$ nanocomposite (long chains, small NPs) to partially dissolved latex beads, $\alpha=41 \%$. The shell model predicts a negligible contribution (included) of the corresponding silica signal as shown in the plot, which is also compared directly to the SANS data (dashed line, see text for details).

If we apply the same shell model to the big NPs, the corresponding prefactor in eq.(10) becomes negligibly small, as it is reduced by a factor of about 17 as mentioned above. In this case, silica is thus expected to remain invisible. If we turn to the case of small NPs in a matrix of long chains, it is also found that silica scattering caused by the shell has no impact on the final intensity. This is not because the shell prefactor is so low, but because the chain scattering is so strong. This is shown in Figure $7 \mathrm{~b}$, where the silica-shell contribution was taken into account for the sake of coherence. It is found to be by a factor of at least 20 below chain scattering, if we take the same shell thickness of $1.6 \mathrm{~nm}$ as before, and this is illustrated by the corresponding low silica intensity in Figure $7 \mathrm{~b}$. In this example, the fits with the Pedersen model reproduce well the intensities for the small silica beads and long chains, for a typical nanocomposite containing $10 \% \mathrm{v}$ of silica. Taking into account the tiny silica shell contribution (which was not the case in Figure 4a), the latex bead dissolution shifts only slightly from $\alpha=40$ to $41 \%$. Note that oscillations are due to the monodispersity assumption of the latex core ${ }^{24}$. For clarity, the SANS intensity has also been superimposed to the silica structure in Figure $7 \mathrm{~b}$. The striking overlap at low angles is due to the similarity in size of silica and latex beads. However, the discrepancy at intermediate angles (arrow at $\approx 510^{-2} \AA^{-1}$ ) 
clearly shows that the silica does not contribute in this case. Altogether, satisfying fits can be produced by taking into account both the latex dissolution - which is chain mass dependent -, and the mismatched shell around NPs - which is controlled by the size of the silica NPs, the two cases being illustrated in Figure $7 \mathrm{a}$ and $7 \mathrm{~b}$.

\section{Conclusion}

We have undertaken a study of filler structure and chain conformation in silica-latex nanocomposites using TEM, SAXS, and SANS under zero average contrast conditions. The effect of silica content has been investigated on four different systems, made of small and big filler NPs, and short and long chains. As a prerequisite to the determination of the chain conformation, the silica structure has been characterized by SAXS and TEM, and NPs were found to be well dispersed for the bigger NPs in the matrix of highest viscosity. Small fractal aggregates were found in all other cases. Note that the ratio between the radius of the silica NPs (radius 5 and $14 \mathrm{~nm}$ ) and radius of gyration of the polymer molecules (3.4 and $9 \mathrm{~nm}$ )

varies by a factor of more than seven, from a situation of big beads/short chains $\left(\mathrm{R}_{\mathrm{Si}} / \mathrm{R}_{\mathrm{g}}=\frac{14}{3.4}=\right.$ $4.1)$ to a situation of small beads/long chains $\left(\frac{5}{9}=0.55\right)$. Even if aggregation can be thought of as an effective increase of NP size, shifting these ratios to higher values, a large range is explored. It is found that the polymer radius of gyration deduced from intermediate and highq scattering using a Debye function is independent of the system, i.e., of the silica size, of the latex-to-silica size ratio, and of the filler content up to $10 \% \mathrm{v}$. With respect to the literature, it may also be emphasized that the scattering function of the short chains is well-identified even in its Guinier regime, and not only at high q. It gives thus a trustworthy measurement of $R_{\mathrm{g}}$, whereas long chains are consistently described with the matrix $\mathrm{R}_{\mathrm{g}}$. At low $\mathrm{q}$, the chain scattering is perturbed by different contributions, which are highlighted separately in the four systems under study. In particular, the presence of silica tends to hinder the dissolution of the latex beads, in a more pronounced manner for smaller beads, and this effect is visible only for the long chains which follow a slow dynamics anyway. The corresponding scattering pattern is characteristic of hairy beads, which are quantitatively described by the Pedersen model previously applied by us to this case. More importantly, the contribution of the theoretically contrast-matched silica is observed, and it is quantitatively important only in the case of small silica NPs and short chains. We have proposed a quantitative model based on a statistical H/D-mismatch in the local environment of the silica NPs. Comparison between scattering 
experiments and the model leads to the determination of a nanometer-thick layer around the filler. The model succeeds in particular in explaining the measured difference of silicavisibility between small and big silica NPs. One may again note that this effect was observed - but never quantitatively described - in the many systems, and that even if the detailed mechanism may be different, the result of a thin shell may serve as a plausible explanation, and our model may serve to evaluate its thickness, if a corresponding model for the shell contrast can be constructed. For instance, Jouault et al 52, 53 recently formulated nanocomposites from solutions of polystyrene/poly(2-vinylpyridine) (PV2P) diblocks with silica NPs (diameter $\approx 14 \mathrm{~nm}$ ). They found that PV2P adsorbs on silica with a nominal grafting density of $\approx 0.01$ chains $/ \mathrm{nm}^{2}$ for a saturated concentration of the adsorbed layer corresponding to $\approx 6$ chains/NP, in close agreement with the estimate of the number of latex beads surrounding a NP in this paper. This small number of adsorbed chains is thus also a feature of small NPs and adsorption from solution - making our conclusions of the importance of small number statistics more general. As a final remark, we insist on the fact that the effect of undesired filler scattering is NP size-dependent - it is pronounced only for smaller beads. This is probably why ZAC turned out to be so difficult with polymer nanocomposites.

Acknowledgments. We acknowledge beam-times on beamlines ID2 by the European Synchrotron Radiation Facility (ESRF, Grenoble), D11 by the Institut Laue Langevin (ILL, Grenoble, France), and KWS2 by the Heinz Maier-Leibnitz Zentrum (MLZ, Garching, Germany). This research project has been supported by the European Commission under the $7^{\text {th }}$ Framework Program through the "Research Infrastructures" action of the Capacities Program, NMI3-II, Grant Agreement number 28388 to perform the neutron scattering measurements at MLZ. Access to TEM measurements at the University of Montpellier and support by F. Godiard and V. Richard are also acknowledged. We are thankful to C. Negrell for TGA measurements and A. Alegria for access to the DSC apparatus in San Sebastian. JO is indebted to the Languedoc-Roussillon region for a "Chercheur d'avenir" grant. 


\section{References}

1 G. Heinrich, M. Kluppel and T. A. Vilgis, Reinforcement of elastomers. Current Opinion in Solid State \& Materials Science, 2002, 6, 195-203.

2 J. Jancar, J. F. Douglas, F. W. Starr, S. K. Kumar, P. Cassagnau, A. J. Lesser, S. S. Sternstein and M. J. Buehler, Current issues in research on structure-property relationships in polymer nanocomposites. Polymer, 2010, 51, 3321-3343.

3 J. E. Mark, B. Erman and F. R. Eirich, Science and Technology of Rubber. Mark, J. E., Ed. Academic Press: San Diego, 1994.

4 G. Schmidt and M. M. Malwitz, Properties of polymer-nanoparticle composites. Current Opinion in Colloid \& Interface Science, 2003, 8, 103-108.

5 J. Oberdisse, Aggregation of colloidal nanoparticles in polymer matrices. Soft Matter, 2006, 2, 29-36.

6 J. Oberdisse, P. Hine and W. Pyckhout-Hintzen, Structure of interacting aggregates of silica particles for elastomer reinforcement. Soft Matter, 2007, 2, 476-485.

7 N. Jouault, F. Dalmas, F. Boue and J. Jestin, Multiscale characterization of filler dispersion and origins of mechanical reinforcement in model nanocomposites. Polymer, 2012, 53, 761-775.

8 S. S. Choi, B. H. Park and H. Song, Influence of filler type and content on properties of styrene-butadiene rubber (SBR) compound reinforced with carbon black or silica. Polymers for Advanced Technologies, 2004, 15, 122-127.

9 G. Capuano, G. Filippone, G. Romeo and D. Acierno, Universal Features of the Melt Elasticity of Interacting Polymer Nanocomposites. Langmuir, 2012, 28, 5458-5463.

10 M. I. Aranguren, E. Mora, J. V. Degroot and C. W. Macosko, Effect of reinforcing fillers on the rheology of polymer melts. Journal of Rheology, 1992, 36, 1165-1182.

11 P. Akcora, S. K. Kumar, J. Moll, S. Lewis, L. S. Schadler, Y. Li, B. C. Benicewicz, A. Sandy, S. Narayanan, J. Illavsky, P. Thiyagarajan, R. H. Colby and J. F. Douglas, "Gellike" Mechanical Reinforcement in Polymer Nanocomposite Melts. Macromolecules, 2010, 43, 1003-1010.

12 J. Berriot, H. Montes, F. Lequeux, D. Long and P. Sotta, Evidence for the shift of the glass transition near the particles in silica-filled elastomers. Macromolecules, 2002, 35, 9756-9762. 
13 A. Papon, H. Montes, F. Lequeux, J. Oberdisse, K. Saalwachter and L. Guy, Solid particles in an elastomer matrix: impact of colloid dispersion and polymer mobility modification on the mechanical properties. Soft Matter, 2012, 8, 4090-4096.

14 A. Papon, K. Saalwächter, K. Schäler, L. Guy, F. Lequeux and H. Montes, Low-Field NMR Investigations of Nanocomposites: Polymer Dynamics and Network Effects. Macromolecules, 2011, 44, 913-922.

15 C. Chevigny, F. Dalmas, E. Di Cola, D. Gigmes, D. Bertin, F. Boué and J. Jestin, Polymer-grafted nanoparticles nanocomposites: dispersion, grafted chain conformation, and rheological behaviour. Macromolecules, 2011, 44, 122-133.

16 S. K. Kumar, N. Jouault, B. Benicewicz and T. Neely, Nanocomposites with Polymer Grafted Nanoparticles. Macromolecules, 2013, 46, 3199-3214.

17 G. P. Baeza, A. C. Genix, C. Degrandcourt, J. Gummel, M. Couty and J. Oberdisse, Mechanism of aggregate formation in simplified industrial silica styrene-butadiene nanocomposites: effect of chain mass and grafting on rheology and structure. Soft Matter, 2014, 10, 6686-6695.

18 G. P. Baeza, A. C. Genix, C. Degrandcourt, J. Gummel, A. Mujtaba, K. Saalwachter, T. Thurn-Albrecht, M. Couty and J. Oberdisse, Studying twin-samples provides evidence for a unique structure-determining parameter in simplified industrial nanocomposites. ACS Macro Letters, 2014, 3, 448-452.

19 G. P. Baeza, A. C. Genix, C. Degrandcourt, L. Petitjean, J. Gummel, R. Schweins, M. Couty and J. Oberdisse, Effect of Grafting on Rheology and Structure of a Simplified Industrial Nanocomposite Silica/SBR. Macromolecules, 2013, 46, 6388-6394.

20 J. P. Cotton, Variations on contrast in SANS: Determination of self and distinct correlation functions. Advances in Colloid and Interface Science, 1996, 69, 1-29.

21 H. C. Benoit and J. S. Higgins, Polymers and neutron scattering. Oxford University Press: Oxford, 1994.

22 S. Sen, Y. P. Xie, S. K. Kumar, H. C. Yang, A. Bansal, D. L. Ho, L. Hall, J. B. Hooper and K. S. Schweizer, Chain conformations and bound-layer correlations in polymer nanocomposites. Physical Review Letters, 2007, 98.

23 A. Tuteja, P. Duxbury and M. Mackay, Polymer Chain Swelling induced by Dispersed Nanoparticles. Phys Rev Lett, 2008, 100, 077801.

24 A. C. Genix, M. Tatou, A. Imaz, J. Forcada, S. R., I. Grillo and J. Oberdisse, Modeling of Intermediate Structures and Chain Conformation in Silica-Latex Nanocomposites Observed by SANS During Annealing. Macromolecules, 2012, 45, 1663-1675. 
25 N. Jouault, F. Dalmas, S. Said, E. Di Cola, R. Schweins, J. Jestin and F. Boué, Direct Measurement of Polymer Chain Conformation in Well-Controlled Model Nanocomposites by Combining SANS and SAXS. Macromolecules, 2010, 43, 98819891.

26 N. Jouault, F. Dalmas, S. Said, E. Di Cola, R. Schweins, J. Jestin and F. Boué, Direct small-angle neutrons scattering observations of stretched chain conformation in nanocomposites:More insight on polymer contributions in mechanical reinforcement. Phys Rev E, 2010, 82, 031801.

27 A. Nakatani, W. Chen, R. Schmidt, G. Gordon and C. Han, Chain dimensions in polysilicate-filled poly(dimethyl siloxane). Polymer, 2001, 42, 3713-3722.

28 K. Nusser, S. Neueder, G. J. Schneider, M. Meyer, W. Pyckhout-Hintzen, L. Willner, A. Radulescu and D. Richter, Conformations of Silica-Poly(ethylene-propylene) Nanocomposites. Macromolecules, 2010, 43, 9837-9847.

29 A. Botti, W. Pyckhout-Hintzen, D. Richter, V. Urban, E. Straube and J. Kohlbrecher, Silica filled elastomers: polymer chain and filler characterization in the undeformed state by a SANS-SAXS approach. Polymer, 2003, 44, 7505-7512.

30 A. Botti, W. Pyckhout-Hintzen, D. Richter, V. Urban and E. Straube, A microscopic look at the reinforcement of silica-filled rubbers. Journal of Chemical Physics, 2006, 124, 174908

31 A. Botti, W. Pyckhout-Hintzen, D. Richter, E. Straube, V. Urban and J. Kohlbrecher, Chain deformation in filled elastomers: a SANS approach. Physica B, 2000, 276, 371372.

32 W.-S. Tung, V. Bird, R. J. Composto, N. Clarke and K. I. Winey, Polymer Chain Conformations in CNT/PS Nanocomposites from Small Angle Neutron Scattering. Macromolecules, 2013, 46, 5345-5354.

33 M. K. Crawford, R. J. Smalley, G. Cohen, B. Hogan, B. Wood, S. K. Kumar, Y. B. Melnichenko, L. He, W. Guise and B. Hammouda, Chain Conformation in Polymer Nanocomposites with Uniformly Dispersed Nanoparticles. Physical Review Letters, 2013, 110, 196001.

34 S. S. Choi, I. S. Kim, S. G. Lee and C. W. Joo, Filler-polymer interactions of styrene and butadiene units in silica-filled styrene-butadiene rubber compounds. Journal of Polymer Science Part B-Polymer Physics, 2004, 42, 577-584.

35 J. Oberdisse, Structure and rheological properties of latex-silica nanocomposite films: Stress-strain isotherms. Macromolecules, 2002, 35, 9441-9450. 
36 M. Tatou, A. C. Genix, A. Imaz, J. Forcada, A. Banc, R. Schweins, I. Grillo and J. Oberdisse, Reinforcement and polymer mobility in silica-latex nanocomposites with controlled aggregation. Macromolecules, 2011, 44, 9029-9039.

37 J. S. Meth, S. G. Zane, C. Chi, J. D. Londono, B. A. Wood, P. Cotts, M. Keating, W. Guise and S. Weigand, Development of Filler Structure in Colloidal Silica-Polymer Nanocomposites. Macromolecules, 2011, 44, 8301-8313.

38 Y. Shinohara, H. Kishimoto, N. Yagi and Y. Amemiya, Microscopic Observation of Aging of Silica Particles in Unvulcanized Rubber. Macromolecules, 2010, 43, 94809487.

39 A. Mujtaba, M. Keller, S. Ilisch, H. J. Radusch, T. Thurn-Albrecht, K. Saalwachter and M. Beiner, Mechanical Properties and Cross-Link Density of Styrene-Butadiene Model Composites Containing Fillers with Bimodal Particle Size Distribution. Macromolecules, 2012, 45, 6504-6515.

40 A. Banc, A. C. Genix, M. Chirat, C. Dupas, S. Caillol, M. Sztucki and J. Oberdisse, Tuning structure and rheology of silica-latex nanocomposites with the molecular weight of matrix chains: a coupled SAXS-TEM-simulation approach. Macromolecules, 2014, 47, 3219-3230.

41 Y. Rharbi, B. Cabane, A. Vacher, M. Joanicot and F. Boue, Modes of deformation in a soft hard nanocomposite: A SANS study. Europhysics Letters, 1999, 46, 472-478.

42 Neutrons, X-ray and Light Scattering. Lindner, P.; Zemb, T., Eds. North Holland, Elsevier: 2002.

43 http://iffwww.iff.kfa-juelich.de/ pipich/dokuwiki/doku.php/qtikws.

44 LAMP, the Large Array Manipulation Program. http://www.ill.eu/data treat/lamp/thelamp-book/.

45 P. G. de Gennes, Scaling Concepts in Polymer Physics. Cornell University Press: Ithaca, New York, 1979.

46 J. S. Pedersen and M. C. Gerstenberg, Scattering form factor of block copolymer micelles. Macromolecules, 1996, 29, 1363-1365.

47 J. S. Pedersen, C. Svaneborg, K. Almdal, I. W. Hamley and R. N. Young, A small-angle neutron and X-ray contrast variation scattering study of the structure of block copolymer micelles: Corona shape and excluded volume interactions. Macromolecules, 2003, 36, 416-433.

48 P. Debye, MOLECULAR-WEIGHT DETERMINATION BY LIGHT SCATTERING. Journal of Physical and Colloid Chemistry, 1947, 51, 18-32. 
49 E. K. Lin, W.-1. Wu and S. K. Satija, Polymer Interdiffusion near an Attractive Solid Substrate. Macromolecules, 1997, 30, 7224-7231.

50 P. Krisanangkura, A. M. Packard, J. Burgher and F. D. Blum, Bound fractions of methacrylate polymers adsorbed on silica using FTIR. Journal of Polymer Science Part B: Polymer Physics, 2010, 48, 1911-1918.

51 J. Moll and S. K. Kumar, Glass Transitions in Highly Attractive Highly Filled Polymer Nanocomposites. Macromolecules, 2012, 45, 1131-1135.

52 N. Jouault, D. Lee, D. Zhao and S. K. Kumar, Block-Copolymer-Mediated Nanoparticle Dispersion and Assembly in Polymer Nanocomposites. Advanced Materials, 2014, 26, 4031-4036.

53 N. Jouault, D. Zhao and S. K. Kumar, Role of Casting Solvent on Nanoparticle Dispersion in Polymer Nanocomposites. Macromolecules, 2014, 47, 5246-5255. 
FOR TABLE OF CONTENTS USE ONLY

On the origin of small-angle scattering from contrast-matched nanoparticles: A study of chain and filler structure in polymer nanocomposites

Amélie Banc, Anne-Caroline Genix, Christelle Dupas, Michael Sztucki, Ralf Schweins, Marie-Sousai Appavou, Julian Oberdisse

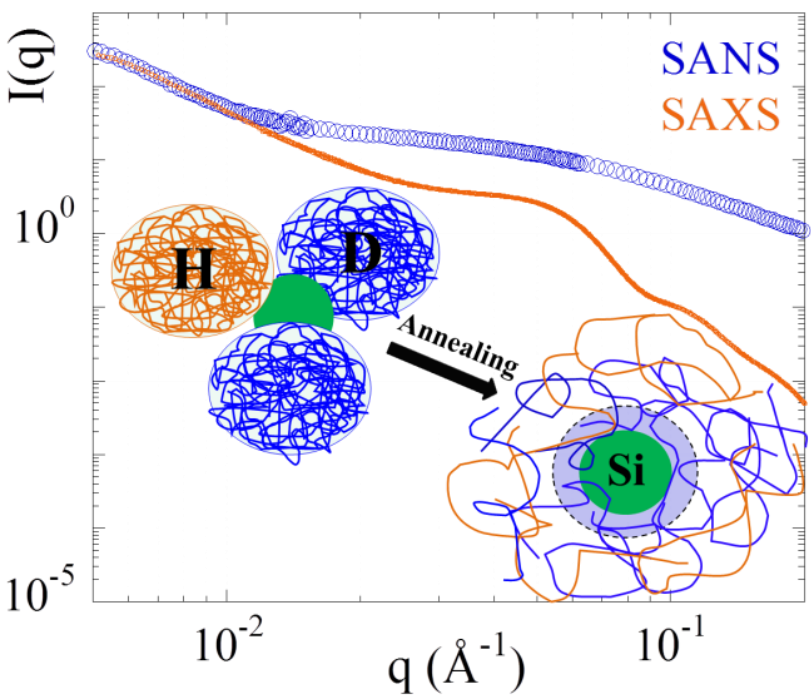

